taining a certain quantity of opium (thirty to forty minims of the tincture). I would specially recommend the linseedtea, as it appears to exercise the same beneficial effect on the ulcers of the large intestine as it does in follicular ulceration of the throat. One of the most obstinate cases of intestinal tubercular ulceration I ever witnessed yielded to linseedtea injections, after almost every other treatment had been vainly tried, the ulcers apparently healing, the diarrhcea ceasing, and the patient living for two years afterwards, and dying of pulmonary lesions. In cases where the stools are very fetid, I have added glycerine of carbolic acid to the injection with advantage. In many cases, however, it is desirable to give the large intestine as much rest as possible, and not to stretch the ulcerated mucous membrane through any distension by fluids; in these cases suppositories of morphia (from half a grain to a grain), or of the compound lead one, or of those of tannic acid are indicated, and the treatment of the diarrhoea arising from lardaceous degeneration of the intestine is not very hopeful. Where the very channels of assimilation-viz., the villi-have undergone degeneration, as well as the various structures from which the succus entericus is poured out, it is difficult to see how treatment can restore the lost tissues. Dr. Dickinson's researches show that the loss of alkali is the chief characteristic of the disease. Dr. Marcet's analyses show that the chief chemical feature is deficiency of phosphoric acid and potash, and excess of soda and chlorine, and on this principle we should give phosphates of potash. When, however, the disease has so far advanced as to reach the intestine, it may he considered beyond any effective general treatment. We must he content to restrain the diarrhcea if we can by astringents, the more powerful the better Tannic acid in from two to four grain doses, with dilute sulphuric acid, sulphate of copper or sulphate of zinc are the most useful, and injections of these substances do some good.

Upper Brook-street, $\mathrm{w}$.

\section{TREATMENT OF COMPOUND FRACTURES AND WOUNDS OF JOINTS BY GLYCERINE AND CARBOLIC ACID.}

By F. C. G. GRIFFIN, M.A., M.B. OxoN., M.R.C.S. ENG., SURGEON TO THE WEYMOUTH ROYAL HOSPITAL.

As various modes of antiseptic treatment continue to be brought forward, and the most opposite opinions are still held as to their merits, $I$ have thought an account of a few cases that I have treated with the glycerinum acidi carbolici of the British Pharmacopœia, without antiseptic spray or any very elaborate precautions, would be of general interest. And although the number of cases is not large, still the fact that they have all got well has produced a strong impression on my mind of the value of this mode of treatment.

A pipe manufacturer of intemperate habits, who had failed in business and taken to fishing, was engaged in hauling in a net, with others, after dark, when he got his leg caught by a loop of rope and was thrown down, and found himself unable to rise. The fishermen carried him home, but handled him rather roughly, as they thought he was not seriously hurt. When I saw him I found he had sustained a compound fracture of the tibia, at the junction of the lower and middle thirds, and had lost a large quantity of blood from a small wound caused by the upper fragment of the tibia having been driven through the skin. I bound it up temporarily, to arrest the bleeding. After about twelve hours, when the bleeding had at length quite stopped, the temporary dressing was removed, and a pad of lint soaked in collodion applied. This pad remained on for two days, when it became partly detached, and free oozing of bloody fluid commenced from the wound. I now applied a pad of four thicknesses of lint saturated with glycerinum acidi carbolici to the wound, and a few turns of bandage over it, so as to keep it in its proper position. The lint became firmly adherent to the wound, and the next day I applied a larger pad of four thicknesses of lint soaked in the same way over the original pad, so as to keep it still saturated. On the third day afterwards I cut the edges of the two outer layers of the pad next the wound, and removed and soaked them with glycerinum acidi carbolici, and then reapplied them, and then the bandage as before. I will here state that I regard it as of much importance to the success of this plan of treatment not to disturb the layers of Jint immediately covering and generally attached to the wound. After this treatment had been continued about ten days, a large blister containing dark fluid formed under the pads and showed at their edges. I now cantiously tried whether the under pad was still adherent, and finding it was not, I removed it and found that the wound had healed. I left the blister exposed to the air, and it dried up in a few days. The remaining progress of the case in no way differed from that of one of simple fracture, and the man ultimately completely recovered. I was informed by this man's wife that previous to the accident he lived almost entirely on beer, and took scarcely any solid food except a little bread, and that if she provided him with a good dinner he used to sell or exchange it for more beer. While he was under my treatment I limited him to a pint of stout daily.

The next patient treated in this way was a boy of about ten years of age, with compound fracture of the tibia, the upper fragment of the bone having been driven through the skin. The glycerinum acidi carbolici was applied on four thicknesses of lint about two hours after the accident, and covered with cotton-wool, and fresh glycerine and acid was applied to the lint daily, without disturbing the layers next the wound. After about ten days the lint was removed, and the wound found to have healed. A speedy recovery followed. The fracture apparatus used was of the same kind as in the following case.

The next patient was a tradesman who had jumped out of a cart while his horse was running away. He in consequence sustained a simple fracture of the fibula and a compound dislocation of the foot outwards, the lower extremity of the tibia being driven through the skin, the sock, and the elastic of his boot against the ground, and the internal malleolus broken off. When he had been conveyed home the bone was still protruding, and the wound could not be got at until his boot and sock had been cut away. The bone, being covered with dirt from the road, was now carefully cleansed, and with the aid of two other surgeons, who had been sent for at the same time as myself, and arrived soon after, an attempt to reduce the dislocation was made. We did not, however, succeed in effecting the reduction until a slice of bone had been sawn off the projecting end of the tibia. After the reduction the limb was placed on an iron back splint, with two wooden slide splints duly padded and suspended from a cradle, the apparatus being of the kind used at St. Bartholomew's Hospital, in the wards of Sir James Paget when he was surgeon there, and supplied by Ferguson, the surgical instrument-maker. About three hours after the accident I syringed out the ankle-joint with a solution of carbolic acid in thirty-nine parts of recently boiled water, and then, after cleaning round the wound, applied a pad of lint of six or eight thicknesses, saturated with glycerinum acidi carbolici, taking care that the upper layers were of sufficient size to project some little way beyond the wound, so as to exclude air effectually, in case of the patient becoming restless. This was then secured by a bandage. The next day all the upper layers of lint were removed, soaked as before, and then reapplied, except the three next the wound, which were left undisturbed. Then over the lint I put a large piece of carbolic acid plaster, and secured it with a bandage. This mode of dressing was repeated night and morning for several weeks, during the whole of which time not more than about a tablespoonful of discharge escaped from beneath the pad of lint. This discharge was of a pink colour, opaque, and nearly solid. The bowels were confined, and pain and starting relieved with tincture of opium, for about a fortnight. After this the patient, who ate heartily his ordinary diet of meat, \&c., the whole time, used to sit up in bed and write letters, and keep the accounts relating to his business. After six weeks I gradually reduced the amount of the carbolic acid by adding more glycerine, and when the wound was nearly healed I used spermaceti ointment. He ultimately made a good recovery, and can walk considerable distances with the aid of two sticks.

The next patient was a cabdriver, aged about fifty years. His horse fell down as he was driving, and while endeavouring to hold him up, he was pulled off his seat, and broke his leg. He was then taken to the Weymouth Royal Hospital, distant seven miles from the scene of the accident. On his arrival there, I found that he had a lacerated wound about 
three inches long, through which the end of the upper half of the tibia was protruding. After the fracture had been set, and the edges of the wound drawn together, except over the seat of fracture, where, in consequence of the swelling of the leg, the skin would not meet without more force being used than appeared desirable, a pad of lint of about four thicknesses was saturated with carbolic acid and glycerine, and lightly bandaged on. The fracture apparatus used consisted of an iron back-splint, with two wooden side-splints, padded and suspended from a cradle, as in the previous case. Over the pad a piece of carbolic-acid plaster was placed. The next day a fresh pad of about four tbicknesses was soaked as befure mentioned, aud applied over the previous one, and the plaster over them both. This dressing was repeated night and morning for about a fortnight, after which it was reduced to once a day. The man was on ordinary diet throughout, and there was no constitutional disturb. ance. About a month after the ascident the lint next the wound was for the first time removed, and the wound found to have healed, except over the end of the bone, where there was a wound about an inch long, with bare bone exposed. The special treatment was now discontinued, and poultices were used. A little later a thin layer of bone came away, and the wound then soon healed, and the man recovered with a useful leg.

The next patient was a brewer's drayman, a large made and very fat man, accustomed to the free use of the beverages he supplied. His horses started off while he was in a public house, and when he ran to their heads and endeavoured to stop them he was knocked down, and hefore they could be stopped the front wheel of the dray going over the inner side of his knee, turned back a large flap of skin, and made a lacerated wound that extended into the kveejoint. A surgeon was called, who dressed the wound, put in some stitches at suitable points, and gave the forezoing account on resioning charge of the case. When I saw him a large pad of four thicknes:es of lint, saturated with the glycerinum acidi carbolici, was apulied over the wound, and kept saturated by fiesh supplies on its outer surface renewed daily. For a week or ten days all went well, and no trouble connected with the joint occurred afterwards, but at the end of that time the lint came off and poultices were used instead, the edues of the skin flap being found to be sloughing, and erysipelas of the leg commencing. The erysipelas followed a severe course, as it did also in several other cases that occurred about the same time, but in the end he recovered and returned to his occupation as drayman.

The next patient was a builder's workman, who fell from a scaffold eighteen feet high, thereby sustaining a severe compound fracture of the lower jaw, while another man falling upon him broke his thigh, and the bone coming through the skin wounded the internal saphenous vein, and caused such copious bleeding that the man appeared in danger of immediate death from loss of blood. Under these circumstances a large sponge was bound tightly over the wound, and the bleeding thus arrested. The fracture was then set, a long splint and bandages being used in the ordi nary way. The treatment haviog reached this stage when I first saw the man, who was cold, perspiring profusely, with livid face, and evidently almost dying from loss of blood, applied the glyeeriuum acidi carbolici freely to the bandages over the sponge, and then lightly bound over them four thicknesses of lint saturated with it. The next day removed the lint, cut slits at short intervals in the bandages, and injected the glycerine through them with a syringe and alunir the upper edge of the sponge, and then reapplied the pad of lint freshly saturated as before. This treatment was continued for a fortnight without disturbing the sponge, after which the sponge was removed, and the wound found to have healed. The man's health improved throughout, and he recovered in about the same time as if it had been a simple fracture of the thigh.

Weymouth.

Mr. Hurchinson commenced his course of lectures on "The Laws of Inheritance in relation to Discase," in the theatre of the Royal College of Surgeons, on Monday last. This lecture, as well as that delivered on WVednesdiy, was attended by an unusually large and appreciative andience, the President of the College in the chair. Sir J. R. Bennett, late President of the Royal Cullege of Physicians, several members of his College, and other distinguished visitors were at the first lecture.

\section{ON SOME}

RARE FORMS OF DISEASE, ACCOMPANIED BY LESIONS OF TROPHIC NERVES OR TROPHIC CENTRES, AND ILLUSTRATIVE OF TROPHIC CHANGES.

By WILLTAM ALEXANDER, M.D., F.R.C.S.

DURING the past two years the surgical practice of the Liverpool Workhouse has presented for observation some rare and interesting forms of disease, all probably dependent upon changes in the nerve centres, and all accompanied by changes that are commonly referred to the disordered action of trophic nerves. The first case seems to be unique in the combination of symptoms. It is similar to no other disease described in our best text-books, and its publication is neces. sary to ascertain whether it has been described before, or if it may be looked upon as an indigenous form of true leprosy.

CASE 1. Irregular symmetrical pigmentation of the body, accompanied by ancesthesia of the pigmented patches.-A delicate girl, ejghteen years of age, was adnisted juto hospital in November, 1879 , suffering frem endo-cervicitis and metritis of gonnrrhoeal origin. The canal of the os uteri was much contracted, and the disease very intractable. This necessitated a prolonged stay in Jompital, and enahled us to test thoroughly the truth of the statements a bout to be made. Shortly after admission a considerable jortinu of the patient's body was found to be covered by a yellowish-bronn pigmen. tation. The upper extremities were almost rovered by it, with the exception of some white spots at the flexures of the elbows, that by contrest with the skin arouvd appeared almost pearly in hue. The thighs were much less stained, and below the knees only a $f \in W$ fugirive spots could be seen. On each chekk there was a small fiant snot. Below the lower lip, and beneath the chin, were distinct median patches, and these two were the only median patches on the body. On the right side the lateral regims of the body were more affected than on the left. On the right the mamma and scapular regions were cocered with pigmenta. tions, whilst on the left the same rf gions nere scarcely touched upon. Over the anterior part of the abdomen, at the inner part of the junction of the Jumbar and iliac regions, were two deeply pigmented sickle-shaped patches. perfectly alike in hue, shape, size, and location on their respective sides of the body. On the dorsal region a few spots existed between the inferior angle of the scafula and the iliac crest. Across the centre of the left iliac crest lay a long crescent shaped patch that was just saved from being as mmetrical by some scattered spots on the opposite side of the body. Like the next disease the pigmentalion was symmetrical, and did not affect the median line except on the face and neck.

The discolouration might be described as brown, brownishyellow, or yellowish-brown. There was no irfiltration of the skin, no elevation of the affected surface, and no evidence of papillary or fungoid growth. Her dank hair had recently become dashed with about oue-sixth of orey. The most important feature of the case remains to he mentionedviz., an easily appreciable and constant amnunt of anxesthesia in the discoloured skin. This was tested by rumerous observers again and again, and though some patches were more anæsthetic than others it was estimated that serisation to touch was one-third less than normal. The anosthesia was in some parts not quite coincident with the piomested areas, but more extensive, and in other places the delangement was more parresthetic than anæsthetic.

Fresent condition (Sept. 1880). - The pigmentation has in. creased considerably, and encruached still further upon the median region of the body. The aurest hesia has alko spread with the plgmentation, but is not more intense than when admitted. Patient has during the last, three mnnths passed through an attack of secondary syphilis, including a scaly rash on the skin, sore-throat, \&c., complicated wiih ovaritis and metritis.

Previous history.-Patient had (up to a few months before admission) always been an active healthy girl until she caught the disease for wbich she came into hospital. She had never been out of Englaud, and never hrd syphilis. When she was five vears of age the brownish marks appeared on the back of the left hand, then spread up that 